\title{
Desenvolvimento de porta-enxertos de umbuzeiro em resposta à adubação com nitrogênio e fósforo
}

\author{
'Umbuzeiro' rootstocks development as a answer for fertilization \\ with nitrogen and phosphorous
}

\begin{abstract}
Alberto Soares de Melo ${ }^{1}$ Marcos Paulo Pacheco Gois ${ }^{2}$ Marcos Eric Barbosa Brito ${ }^{3}$ Pedro Roberto Almeida Viégas ${ }^{4}$ Francisco Pinheiro de Araújo $^{5}$ Dangelly Lins Martins Figuerôa de Mélo ${ }^{6}$ Marcelo da Costa Mendonça ${ }^{7}$
\end{abstract}

\section{RESUMO}

A adubação, notadamente com nitrogênio e fósforo, é fundamental no estádio de desenvolvimento inicial de mudas de frutíferas. Porém, existem poucas informações científicas com respeito do umbuzeiro. Assim, objetivou-se avaliar o efeito de doses de nitrogênio e fósforo no desenvolvimento de portaenxertos de umbuzeiro (Spondias tuberosa Arr. Câm.). O experimento foi conduzido sob telado, na Universidade Federal de Sergipe, em um delineamento em blocos ao acaso, em esquema fatorial $4 \times 4$, sendo quatro níveis de nitrogênio e quatro de fósforo $\left(0,50,100\right.$ e $150 \mathrm{~kg} \mathrm{ha}^{-1}$ de $\mathrm{N}$ e $\mathrm{P}_{2} \mathrm{O}_{5}$, respectivamente na forma de uréia e superfosfato simples, em quatro repetições. $O$ maior ganho em altura $(12,52 \mathrm{~cm})$ foi obtido com as doses de 97,58kg $h a^{-1}$ de $N$, enquanto o maior incremento no diâmetro do colo (2,18mm) foi obtido com as doses de $150 \mathrm{~kg} \mathrm{ha}^{-1}$ de $\mathrm{Ne} 150 \mathrm{~kg} \mathrm{ha}^{-1}$ de $\mathrm{P}_{2} \mathrm{O}_{5}$. $\mathrm{O}$ maior número de folhas foi observado na presença de $126,03 \mathrm{~kg} \mathrm{ha}^{-1}$ de $\mathrm{N}$ e $150 \mathrm{~kg} \mathrm{ha} \mathrm{g}^{-1}$ de $\mathrm{P}_{2} \mathrm{O}_{5}$. A maior produção de massa seca da parte aérea total foi constatada na dose de $98,71 \mathrm{~kg}$ $h a^{-1}$ de $\mathrm{N}$ e $150 \mathrm{~kg} \mathrm{ha}^{-1}$ de $\mathrm{P}_{2} \mathrm{O}_{5}$. A área foliar cresceu linearmente para ambos fatores As adubações estudadas contribuem de forma positiva para a formação de mudas de umbuzeiro, podendo antecipar a formação de porta-enxertos para algumas fruteiras do gênero Spondias. Doses de fósforo a partir de $150 \mathrm{~kg} \mathrm{ha}^{-1}$ não são recomendadas quando se pretende produzir picles, a partir do xilopódio do umbuzeiro.

\begin{abstract}
The fertilization, notable with nitrogen and phosphorous, is fundamental on initial development stadium on fruits nursery trees. However, there is little scientific information about 'umbuzeiro'. This work had as objective to evaluate the effect of nitrogen and phosphorous' doses on 'umbuzeiro' rootstocks (Spondias tuberosa Arr. Câm.). The experiment was carried out under nursery at 'Universidade Federal de Sergipe' being used experimental design of randomized blocks in factorial $4 X 4$ with four levels of nitrogen and four levels of phosphorous $\left(0,50,100\right.$ and $150 \mathrm{~kg} \mathrm{ha}^{-1}$ of $\mathrm{N}$ and $\left.\mathrm{P}_{2} \mathrm{O}_{5}\right)$ respectively under urea form and simple superphosphate, with four replications. The higher rootstock $(12.52 \mathrm{~cm})$ was obtained with doses of $97.58 \mathrm{~kg}$ $\mathrm{ha}^{-1}$ of $\mathrm{N}$, the higher stem diameter $(2.18 \mathrm{~mm})$ was obtained with doses of $150 \mathrm{~kg} \mathrm{ha}^{-1}$ of $\mathrm{N}$ and $150 \mathrm{~kg} \mathrm{ha}^{-1}$ of $\mathrm{P}_{2} \mathrm{O}_{5}$. The major number of leaves was observed on presence of $126.03 \mathrm{~kg} \mathrm{ha}^{-1}$ of $N$ and $150 \mathrm{~kg} \mathrm{ha}-1$ of $\mathrm{P}_{2} \mathrm{O}_{5}$. The major dry matter production of total aerial plant was verified with a dose of $98.71 \mathrm{~kg} \mathrm{ha}^{-1}$ of $N$ and $150 \mathrm{~kg} \mathrm{ha} \mathrm{a}^{-1}$ of $\mathrm{P}_{2} \mathrm{O}_{5}$. The leaf area presented a linear grown for both factors. The nitrogen and phosphorous fertilization contribute as positive performance on 'umbuzeiro' doing the rootstocks development anticipated for some fruit trees of the Spondias genus. Phosphorous' doses from $150 \mathrm{~kg} \mathrm{ha}^{-1}$ were not recommended for pickles production using 'umbuzeiro' xylopodium.
\end{abstract}

Key words: Spondias tuberosa; 'umbu'; crop fruit.

${ }^{1}$ Engenheiro Agrônomo, MSc, Fitotecnia, Doutorando em Recursos Naturais da Universidade Federal de Campina Grande (UFCG). Professor do Departamento de Engenharia Agronômica da Universidade Federal de Sergipe (UFS), 49100-000, São Cristóvão, SE. Email: asoaresmelo@ufs.br. Autor para correspondência.

${ }^{2}$ Engenheiro Agrônomo da Universidade Federal de Sergipe, 49100-000, São Cristóvão, SE.

${ }^{3}$ Aluno do Curso de Engenharia Agronômica, UFS, bolsista do Programa de Iniciação Científica (PIBIC), Conselho Nacional de Desenvolvimento Científico e Tecnológico (CNPq).

${ }^{4}$ Engenheiro Agrônomo, Doutor, Nutrição de Plantas, Professor do Departamento de Engenharia Agronômica da UFS.

${ }^{5}$ Engenheiro Agrônomo, MSc, Fitotecnia, Pesquisador da Empresa Brasileira de Pesquisa Agropecuária (Embrapa) Semi-Árido. Petrolina, PE.

${ }^{6}$ Engenheiro Agrônomo, Aluno de Mestrado do Núcleo de Estudos do Semi-Árido da UFS.

${ }^{7}$ Engenheiro Agrônomo, MSc, Ciências Agrárias, Professor da UFS. 


\section{INTRODUÇÃO}

O reconhecido potencial econômico das Spondias (cajarana, cajazeira, ciriguela, umbu e umbuguela) tem despertado o interesse de pesquisadores e produtores, em virtude das possibilidades da utilização de seus frutos no preparo de sucos, doces e sorvetes, além da extração de goma (ARAÚJO et al., 2001). Saliente-se que o crescente interesse torna-se ainda maior devido à demanda de frutos com sabores exóticos, pelos mercados internacionais.

O mercado brasileiro de sucos prontos para beber é um setor que tem crescido a cada ano. Estimase que em 2000 foram consumidos no Brasil 235 milhões de litros de sucos, um crescimento de quase $40 \%$ em relação a 1999, o que movimentou cerca de 294 milhões de reais e representa um forte indicativo de crescimento para a agroindústria do setor (REVISTA PODER, 2002). Neste contexto, o Nordeste brasileiro se destaca no cenário nacional, principalmente quanto à produção de suco concentrado, que é geralmente exportado ou vendido para as indústrias de sorvetes e de sucos. No grupo, ressalta-se o umbu, cuja demanda tem crescido acentuadamente. Além disso, dentre as alternativas de agronegócios criadas a partir deste, a produção de picles da túbera da planta, pode ser uma alternativa promissora.

No Estado de Sergipe, onde o umbuzeiro encontra-se praticamente devastado pela ação predatória do homem, necessita-se de um programa de incentivo à preservação desta espécie, bem como a implantação de variedades melhoradas geneticamente, a exemplo do que vem ocorrendo em outros Estados do Nordeste, mais precisamente em Pernambuco.

Os umbuzeiros existentes em Sergipe apresentam, de modo geral, reduzida produtividade de frutos. Isto leva a acreditar que um possível desequilíbrio nutricional nos solos do Semi-Árido sergipano, atrelado a grande variabilidade genética, possam estar interferindo no baixo rendimento dessa fruteira. Assim, programas de nutrição devem ser criados a fim de sanar tal problema.

Apesar da importância real e potencial que a espécie apresenta, verifica-se que existem poucas informações científicas ao seu respeito, notadamente sobre exigências nutricionais (GONZAGANETO et al., 1989). CAVALCANTI et al. (2002), estudando diferentes substratos no crescimento de mudas de umbuzeiro, constataram que as maiores alturas foram obtidas com esterco de bovino e terra e aplicação de $237 \mathrm{mg} \mathrm{dm}^{-3}$ de P. Por sua vez, BERNARDI et al.
(2000), analisando o desenvolvimento de mudas de citros em vaso, observaram interação positiva entre $\mathrm{N}$ e P no crescimento das mudas. Já MELO (1999), estudando doses de $\mathrm{N}$ e $\mathrm{P}$ em mudas de aceroleira, encontrou respostas significativas à adubação fosfatada para o diâmetro do caule que é uma característica que determina o ponto de enxertia. Os autores acima citados reportam que estes elementos participam dos metabolismos vitais de crescimento das plantas. Desse modo, conhecer tais exigências pelo umbuzeiro, na sua fase inicial de desenvolvimento, e associá-las à aplicação de quantidades adequadas de fertilizantes, é uma das estratégias para estabelecer-se um programa racional e eficiente de nutrição para a espécie.

O presente trabalho teve como objetivo avaliar o efeito de doses de nitrogênio e fósforo na produção de mudas de umbuzeiro para utilização como porta-enxertos de algumas espécies do gênero Spondias.

\section{MATERIAL E MÉTODOS}

O experimento foi conduzido sob telado, no Campus Rural do Departamento de Engenharia Agronômica da Universidade Federal de Sergipe, localizado no município de São Cristóvão - SE. O delineamento experimental foi em blocos ao acaso em um esquema fatorial, considerando-se dois fatores (nitrogênio e fósforo, na forma de uréia e superfosfato simples) com quatro níveis cada $(0,50,100$ e $150 \mathrm{~kg}$ ha $^{-1}$ de $\mathrm{N}$ e $\mathrm{P}_{2} \mathrm{O}_{5}$ ), em quatro repetições.

As mudas de umbuzeiro foram produzidas por meio de sementes provenientes de uma planta matriz situada no Campo Experimental da Caatinga da Embrapa Semi-Árido, município de Petrolina-PE.

Para uniformizar a germinação, efetuou-se a quebra da dormência das sementes (ARAÚJO et al., 2001). Em seguida, foram semeadas na profundidade média de $2,5 \mathrm{~cm}$, diretamente em sacos de polietileno com capacidade média de 1,5 litro de solo. Colocaramse duas sementes por saco. Após germinadas, 35 dias depois da semeadura, efetuou-se o desbaste deixandose apenas uma plântula.

O solo utilizado foi o Argissolo VermelhoAmarelo eutrófico (EMBRAPA, 1999) proveniente do município de Feira Nova-SE, situado na região SemiÁrida, e apresentou as seguintes características na camada de 0-20cm: $\mathrm{pH}$ em água $=6,0 ; \mathrm{P}=4,30 \mathrm{mg}$ $\mathrm{dm}^{-3} ; \mathrm{K}^{+}=0,75 ; \mathrm{Ca}^{++}+\mathrm{Mg}^{++}=6,42 ; \mathrm{Na}^{+}=0,16 ; \mathrm{Al}^{3+}=0,0$; $\mathrm{H}+\mathrm{Al}^{3+}=2,97 ; \mathrm{CTC}=10,30 \mathrm{em} \mathrm{cmol}_{\mathrm{c}} \mathrm{dm}^{-3} ;$ Matéria Orgânica $=3,50 \mathrm{dag} \mathrm{dm}^{-3} ; \mathrm{V}(\%)=71 ;$ Capacidade de Campo $(\%)$ a $0,33 \mathrm{~atm}=27,46$; Ponto de Murcha $(\%)$ a $15 \mathrm{~atm}=7,04$. 
Os tratamentos com fósforo foram misturados à terra individualmente e os tratamentos com nitrogênio foram parcelados (1/2 aos 65 dias e 1/ 2 aos 80 dias após a semeadura). As irrigações foram efetuadas de acordo com a capacidade de campo do substrato e necessidades hídricas das plântulas.

Os dados do experimento foram coletados aos 135 dias após a semeadura, quando as plantas estavam, em média, com idade de três meses e meio (105 dias). As variáveis avaliadas foram: altura da planta, ALTP (cm), diâmetro do colo, DC (mm), número de folhas, NF, massa seca da parte aérea total, $\operatorname{MSPAT}(\mathrm{g})$, área foliar, $\mathrm{AF}\left(\mathrm{cm}^{2}\right)$ e comprimento, CX e diâmetro do xilopódio, DX $(\mathrm{cm})$. A leitura da área foliar foi feita no Planímetro Model 3100 Area Meter.

Os dados obtidos foram analisados estatisticamente, utilizando-se o programa SAEG 8.0, e os modelos de regressão foram ajustados pelo programa Table Curve 3D, conforme o coeficiente de regressão até $10 \%$ de probabilidade pelo teste t.

\section{RESULTADOS E DISCUSSÃO}

Verifica-se na figura 1A, que o ganho médio para ALTP apresentou um comportamento quadrático na presença das doses de $\mathrm{N}$, com alta capacidade preditiva $(\mathrm{P}<0,01)$. No entanto, não diferiu na presença de P. O ganho médio ALTP máximo $(12,52 \mathrm{~cm})$ foi obtido na dose estimada de $98 \mathrm{~kg} \mathrm{ha}^{-1}$ de $\mathrm{N}$. CAVALCANTI et al. (2002), estudando diferentes substratos no crescimento de mudas de umbuzeiro, constataram que as maiores alturas foram obtidas com esterco de bovino e solo, com $237 \mathrm{mg} \mathrm{dm}^{-3}$ P. Por sua vez, BERNARDI et al. (2000), analisando o desenvolvimento de mudas de citros em vaso, observaram interação positiva entre $\mathrm{N}$ e $\mathrm{P}$ no crescimento das mudas.

Neste estudo, o ganho em altura das mudas de umbuzeiro foi alto (156\%) quando comparado ao tratamento não fertilizado com $\mathrm{N}$, onde as mudas emitiram poucos ramos e, muitas vezes, manifestavam gemas ainda dormentes. Tais resultados evidenciam a participação deste nutriente na constituição de proteínas essenciais no crescimento vegetal (MOORBY \& BESFORD, 1983). Para os autores, a carência de $\mathrm{N}$ implica inibição da síntese protéica afetando o processo de divisão celular.

Quanto à variável DC (mm), observa-se na figura 1B um comportamento linear crescente dos efeitos de $\mathrm{N}(\mathrm{P}<0,10)$ e $\mathrm{P}(\mathrm{P}<0,01)$. O incremento máximo médio estimado foi de $2,18 \mathrm{~mm}$ na dose máxima dos dois fatores $\left(150 \mathrm{~kg} \mathrm{ha}^{-1} \mathrm{de} \mathrm{N}\right.$ e $150 \mathrm{~kg} \mathrm{ha}^{-1}$ de $\mathrm{P}_{2} \mathrm{O}_{5}$ ) . Nota-se, ainda, um efeito mais pronunciado do P, evidenciando a importância deste nutriente na antecipação do tempo de enxertia do umbuzeiro. MELO (1999), estudando níveis de N e P em mudas de aceroleira, encontrou respostas significativas à adubação fosfatada para este parâmetro. De acordo com o autor, o diâmetro do caule é uma característica morfológica do porta-enxerto que determina o ponto de enxertia e o sucesso do pegamento no processo de formação de mudas.

Analisando-se a figura $2 \mathrm{~A}$, verificou-se um comportamento quadrático do efeito de $\mathrm{N}(\mathrm{P}<0,10)$ e um efeito linear crescente para os níveis de $\mathrm{P}(\mathrm{P}<0,10)$ no NF. Na presença conjunta do máximo estimado de $\mathrm{N}\left(126,03 \mathrm{~kg} \mathrm{ha}^{-1}\right)$ e do maior nível de $\mathrm{P}\left(150 \mathrm{~kg} \mathrm{ha}^{-1}\right.$ de $\mathrm{P}_{2} \mathrm{O}_{5}$ ), evidenciou-se um ganho médio do NF da ordem de 7,93 folhas por muda. A observação visual das mudas de umbuzeiro permitiu constatar que as plantas que foram submetidas aos tratamentos sem $\mathrm{N}$, apresentaram suas folhas concentradas na parte apical do caule, diferentemente das outras plantas que tinham as folhas distribuídas ao longo do caule. É importante salientar que a distribuição das folhas ao longo do caule é uma característica importante, pois isso implica um maior dossel de captação de luz pelas mudas de umbuzeiro.

A produção de MSPAT (g) das mudas de umbuzeiro variou de forma quadrática ao fornecimento de $\mathrm{N}(\mathrm{P}<0,10)$, enquanto para o suprimento de $\mathrm{P}$ $(\mathrm{P}<0,10)$ a variação se apresentou de forma linear crescente (Figura $2 \mathrm{~B}$ ). Denota-se que a produção de MSPAT (2,27 g) máxima estimada foi obtida na dose de $98,71 \mathrm{~kg} \mathrm{ha}^{-1}$ de $\mathrm{N}$ na ausência de P. Por sua vez, na interação $\mathrm{N} x$ P teve-se um ganho estimado máximo de 3,33g. BERNARDI et al. (2000), estudando a produção de mudas de citros em vaso, observaram que o $\mathrm{N}$ promoveu efeito quadrático significativo na produção da massa seca de mudas da laranjeira Valência. Constataram, ainda, que na dose de $1,25 \mathrm{~g}$ de $\mathrm{N}$ por planta, a produção foi de $13,63 \mathrm{~g}$ de massa seca e a produção máxima de $14,77 \mathrm{~g}$ de massa seca foi obtida com a dose de $6,02 \mathrm{~g}$ por planta. A importância do $\mathrm{N}$ na produção da massa seca da parte aérea foi testada por PEREIRA et al. (1996), observando a influência positiva de N no crescimento de mudas de árvores e, por PEIXOTO \& CARVALHO (1996), avaliando o efeito da uréia na formação de mudas de maracujazeiro amarelo. Estes evidenciaram que a produção da matéria seca da parte aérea foi maior com o aumento das doses desse nutriente.

Analisando a figura $3 \mathrm{~A}$, verifica-se que os resultados obtidos para a $\mathrm{AF}\left(\mathrm{cm}^{2}\right)$ tiveram efeito linear crescente do $\mathrm{N}(\mathrm{P}<0,01)$ e $\mathrm{P}(\mathrm{P}<0,10)$. $\mathrm{O}$ valor estimado da área foliar para as doses máximas de $\mathrm{N}$ e

Ciência Rural, v.35, n.2, mar-abr, 2005. 
(A)

$$
\begin{gathered}
y=4,89406+0,156256^{* *} N-0,000800625^{* *} N^{2} \\
R^{2}=0,7179
\end{gathered}
$$

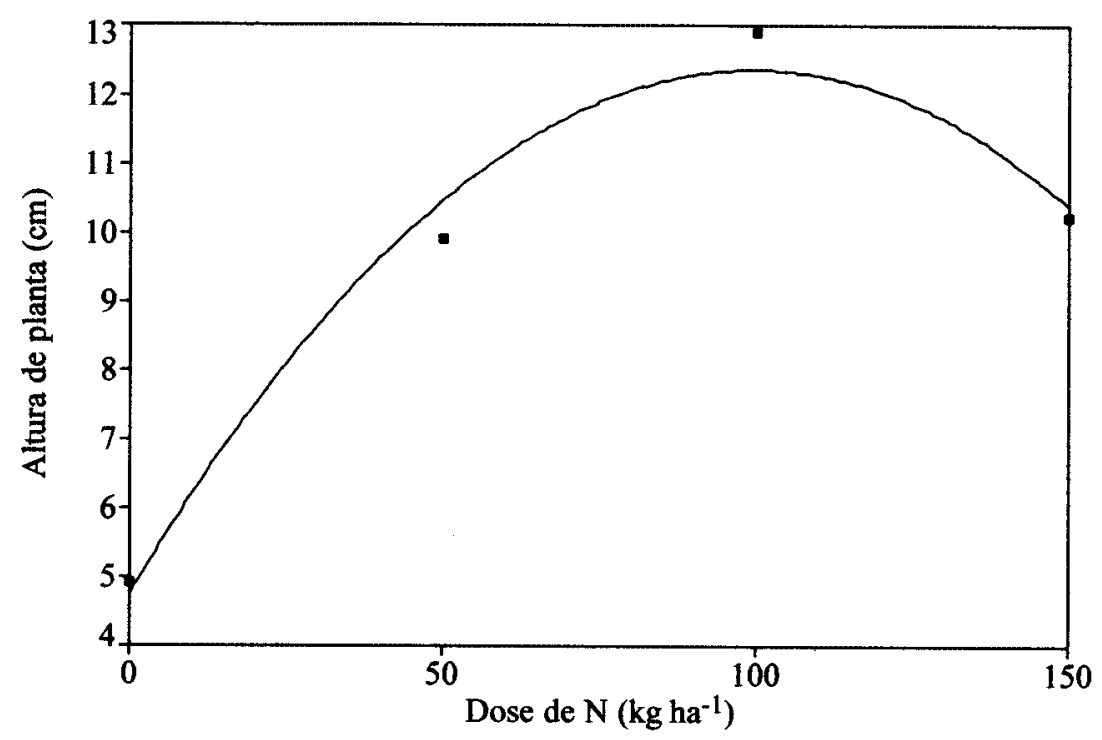

(B)

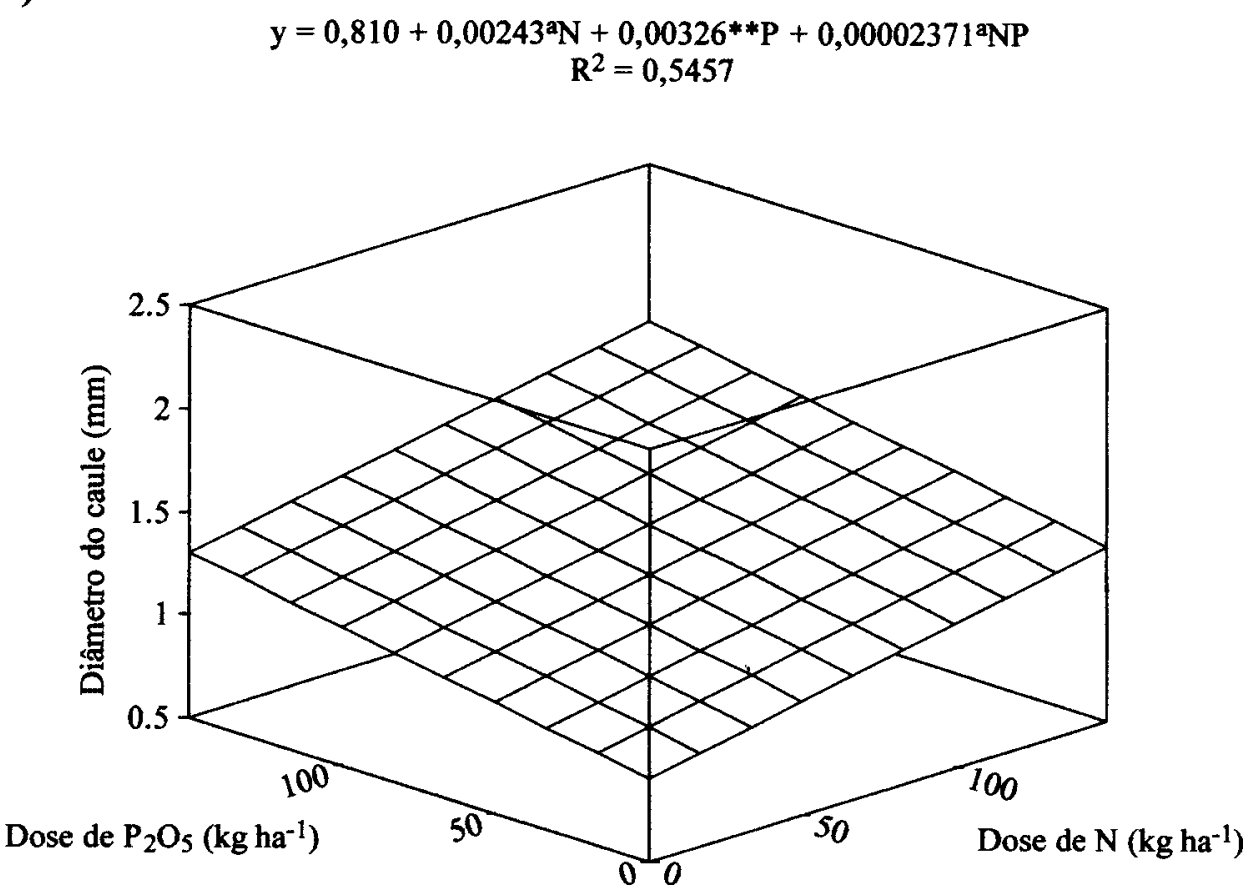

Figura 1 - Efeito da adubação isolada do N ou combinada com P na ALTP (A) e no diâmetro do caule (B) em mudas de umbuzeiro.

Ciência Rural, v.35, n.2, mar-abr, 2005. 
(A)

$$
y=2,50+0,061^{*} N+0,000242^{a} N^{2}+0,00095^{a} P+0,000064^{a} N P
$$
$\mathrm{R}^{2}=0,6097$

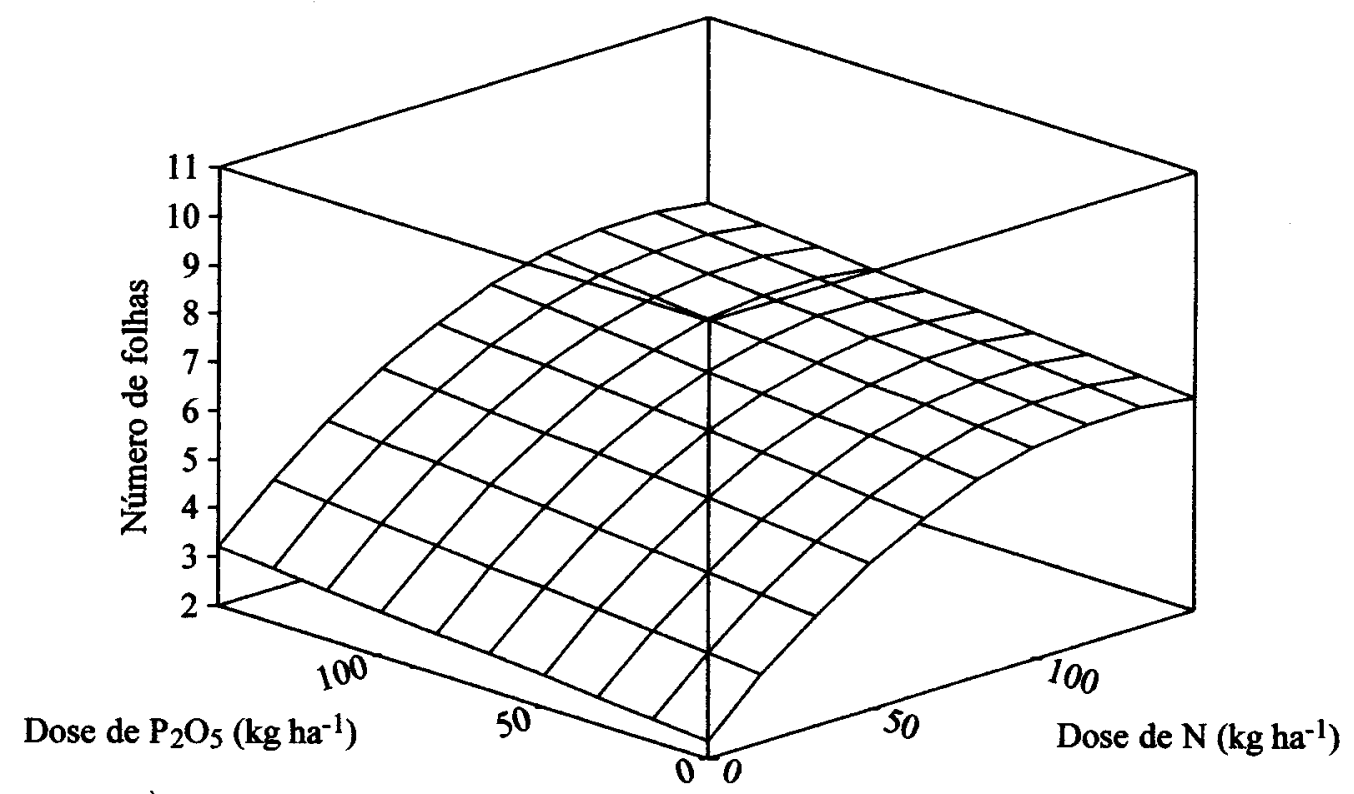

(B)

$$
\begin{gathered}
y=1,37+0,0183^{*} N-0,0000927^{a} N^{2}+0,00016^{a} P+0,000046^{*} N P \\
R^{2}=0,5957
\end{gathered}
$$

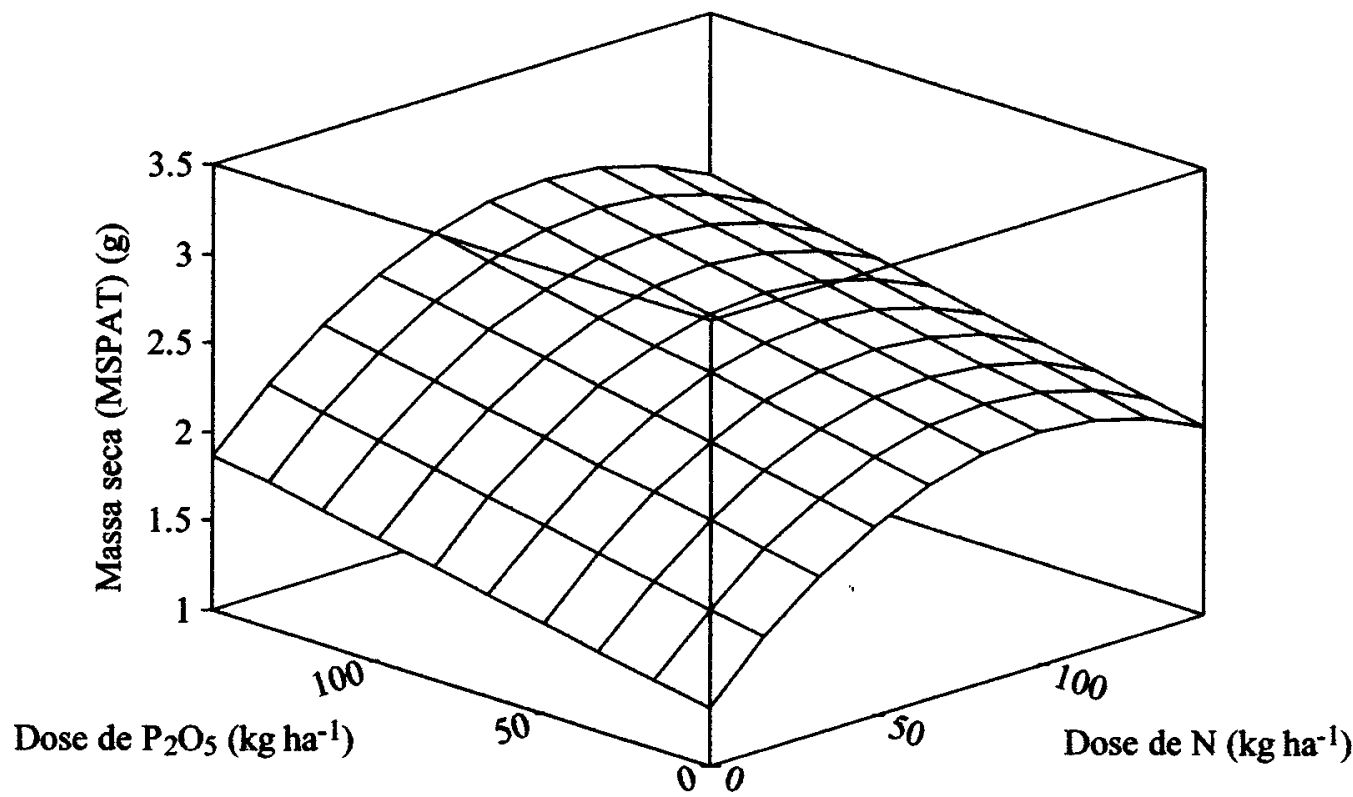

Figura 2 - Efeito da adubação combinada do N com P no NF (A) e na MSPAT (B) em mudas de umbuzeiro.

Ciência Rural, v.35, n.2, mar-abr, 2005. 
(A)

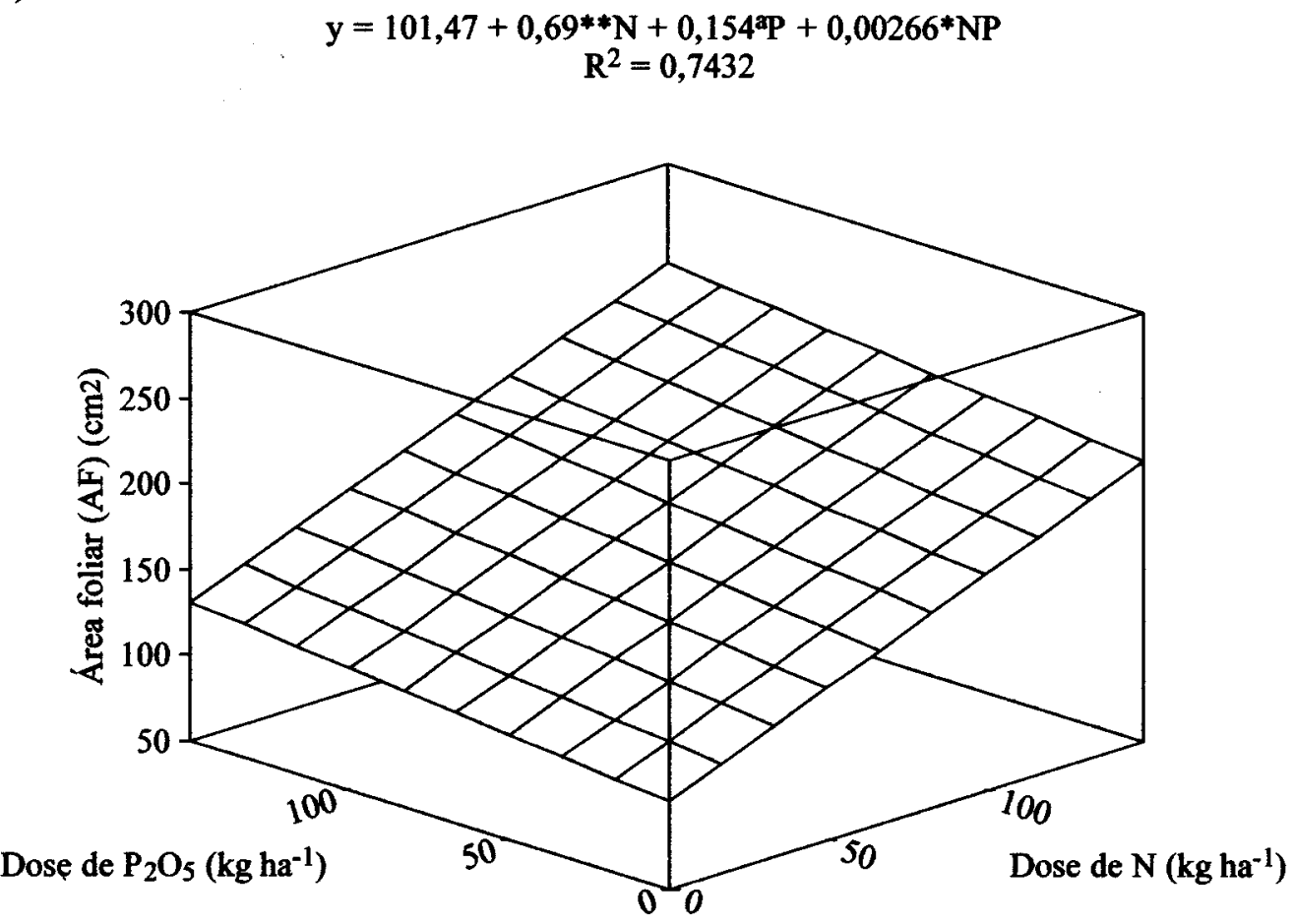

(B)

$$
y=8,63+0,0472^{2} \mathrm{~N}-0,00021^{a} \mathrm{~N}^{2}+0,00575^{*} \mathrm{P}+0,000035^{\mathrm{a}} \mathrm{NP}
$$
$R^{2}=0,7802$

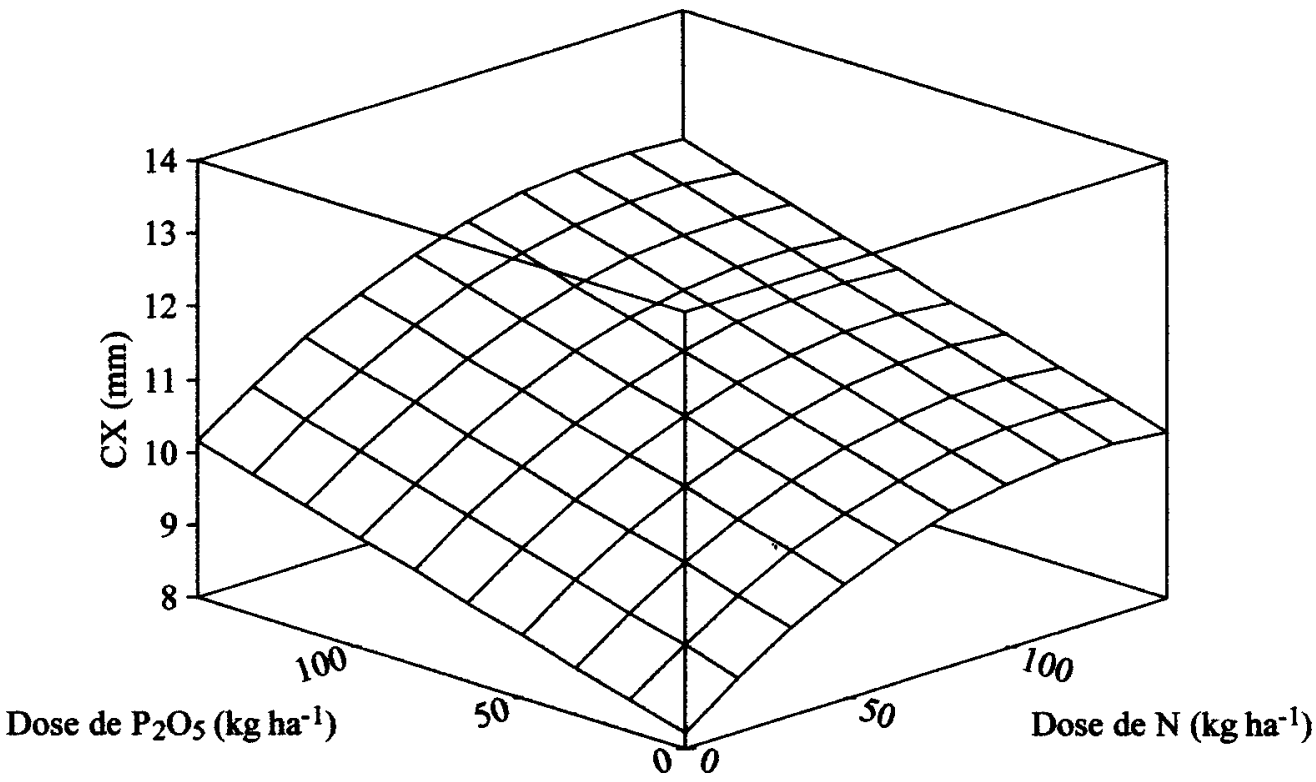

Figura 3 - Efeito da adubação combinada do N com P na AF (A) e no CX (B) em mudas de umbuzeiro.

Ciência Rural, v.35, n.2, mar-abr, 2005. 
$\mathrm{P}\left(150 \mathrm{~kg} \mathrm{ha}^{-1}\right.$ de $\mathrm{N}$ e $150 \mathrm{~kg} \mathrm{ha}^{-1}$ de $\mathrm{P}_{2} \mathrm{O}_{5}$ ) foi de $285,92 \mathrm{~cm}^{2}$. A análise da $\mathrm{AF}$ e a do NF são importantes por evidenciar as folhas como fonte de produção de seiva orgânica que exerce papel fundamental no crescimento das plantas (SALISBURY \& ROSS, 1991).

Analisando o CX (Figura 3B), verificouse um efeito quadrático para o fator $\mathrm{N}(\mathrm{P}<0,10)$ e linear crescente para $\mathrm{P}(\mathrm{P}<0,10)$. O comprimento máximo $(11,28 \mathrm{~cm})$ foi obtido na dose estimada de $112,4 \mathrm{~kg}$ $\mathrm{ha}^{-1}$ de $\mathrm{N}$, estudando o $\mathrm{N}$ isoladamente. $\mathrm{Na}$ presença da máxima dose de $\mathrm{P}\left(150 \mathrm{~kg} \mathrm{ha}^{-1}\right.$ de $\left.\mathrm{P}_{2} \mathrm{O}_{5}\right)$, o comprimento do xilopódio foi de $12,93 \mathrm{~cm}$. CAVALCANTI et al. (2002), testando o crescimento do umbuzeiro em diferentes substratos, observaram que os xilopódios das plântulas cultivadas em solo com $4 \mathrm{mg} \mathrm{dm}^{-3}$ de $\mathrm{P}$ apresentaram menor comprimento $(6,53 \mathrm{~cm})$ que os demais substratos estudados, aos 30 dias após a semeadura. Os autores verificaram que o substrato composto de areia + solo adubado com $258 \mathrm{mg} \mathrm{dm}^{-3} \mathrm{de} \mathrm{P}$ proporcionou o desenvolvimento dos maiores xilopódios, com até $8,97 \mathrm{~cm}$ de comprimento.

Ressalte-se no presente trabalho, que as mudas que receberam as doses mais elevadas do fertilizante fosfatado $\left(150 \mathrm{~kg} \mathrm{ha}^{-1}\right.$ de $\mathrm{P}_{2} \mathrm{O}_{5}$ ), apresentaram algum tipo de deformação do xilopódio. Deste modo, quando se deseja produzir picles a partir das túberas, doses de $\mathrm{P}$ a partir de $150 \mathrm{~kg} \mathrm{ha}^{-1} \mathrm{de}_{2} \mathrm{P}_{5}$ são desaconselháveis.

Para o parâmetro DX, foi verificado que não houve diferença significativa entre os tratamentos. Visualmente, o que se observou foi a formação de mais de um xilopódio nas plantas que receberam $100 \mathrm{~kg} \mathrm{ha}^{-1}$ de $\mathrm{N}$ e $150 \mathrm{~kg} \mathrm{ha}^{-1}$ de $\mathrm{P}_{2} \mathrm{O}_{5}$.

A análise da tabela 1, utilizando-se os 64 pares de dados, permite verificar que a correlação entre as variáveis estudadas é altamente significativa, apesar de algumas correlações apresentarem baixa capacidade preditiva. Os coeficientes de correlação variaram de 0,2333 para ALTP x CX, até 0,7906 para MSPAT x AF.

Tabela 1 - Matriz de correlação dos parâmetros estudados: altura (ALTP), número de folhas (NF), diâmetro do caule (DC) de mudas de umbuzeiro, massa seca da parte aérea total (MSPAT), área foliar (AF) e comprimento do xilopódio (CX).

\begin{tabular}{lcccccc}
\hline & ALTP & DC & NF & MSPAT & AF & CX \\
\hline ALTP & ------ & $0,4946 * *$ & $0,5156 * *$ & $0,4951 * *$ & $0,5986 * *$ & $0,2333^{*}$ \\
DC & ----- & ----- & $0,2954 * *$ & $0,5680 * *$ & $0,5108 * *$ & $0,3152 * *$ \\
NF & ----- & ----- & ----- & $0,3570 * *$ & $0,5487 * *$ & $0,2792 * *$ \\
MSPAT & ------ & ----- & ----- & ----- & $0,7906 * *$ & $0,6205 * *$ \\
AF & ------ & ------ & ----- & ----- & ----- & $0,5567 * *$ \\
\hline
\end{tabular}

**; * significativo a $1 \%$ e $5 \%$ respectivamente, pelo teste $\mathrm{t}$.
Sabendo-se que as variáveis mais indicadas para avaliar o desenvolvimento de porta-enxertos são ALTP, DC, MSPAT e AF, na tabela 1 tem-se a evidência da existência de correlação positiva $(\mathrm{P}<0,01)$ entre essas variáveis. É possível constatar na matriz de correlação, um forte indicador da taxa de crescimento da muda de umbuzeiro, por meio da análise da MSPAT e AF $(\mathrm{P}<0,01)$, bem como o DC e AF $(\mathrm{P}<0,01)$. As correlações entre MSPAT, AF e CX são importantes para se inferir de que forma o sistema radicular participa do suprimento nutricional da parte aérea da planta e vice-versa. Ressalte-se que correlações positivas são levadas em conta na escolha da melhor idade para efetuar a prática de enxertia, em função do crescimento mínimo atingido pelas mudas.

\section{CONCLUSÕES}

A adubação nitrogenada e a fosfatada contribuíram de forma positiva para o desenvolvimento inicial de mudas de umbuzeiro, o que pode antecipar a formação de porta-enxertos para algumas fruteiras do gênero das Spondias. Mudas de umbuzeiro têm maior acúmulo de massa seca da parte aérea total $(\mathrm{g})$ em resposta à adubação com $98,71 \mathrm{~kg}$ $\mathrm{ha}^{-1}$ de $\mathrm{N}$ e $150 \mathrm{~kg} \mathrm{ha}^{-1} \mathrm{P}_{2} \mathrm{O}_{5}$. Doses de fósforo a partir de $150 \mathrm{~kg} \mathrm{ha}^{-1}$ não são recomendadas quando se pretende produzir picles, a partir do xilopódio do umbuzeiro.

\section{REFERÊNCIAS BIBLIOGRÁFICAS}

ARAÚJO, F.P. de et al. Influência do período de armazenamento das sementes de umbuzeiro na germinação e no desenvolvimento da plântula. Revista Brasileira de Armazenamento, v.26, n.2, p.36-39, 2001.

BERNARDI, A.C. de C. et al. Desenvolvimento de mudas de citros cultivadas em vaso em resposta à adubação NPK. Scientia Agricola, v.57, n.4, p.733-738, 2000.

CALVALCANTI, N. de B. et al. Emergência e crescimento do imbuzeiro (Spondias tuberosa, Arr. Câm.) em diferentes substratos. Revista Ceres, v.49, n.282, p.97-108, 2002.

EMBRAPA. Centro Nacional de Pesquisa de Solos (Rio de Janeiro, RJ). Sistema brasileiro de classificação de solos. Brasília : Embrapa Produção de Informação; Rio de Janeiro: Embrapa Solos, 1999. 412p.

GONZAGA NETO, L. et al. Estudo de enraizamento de estacas de umbuzeiro (Spondias tuberosa, Arr. Câm.). Revista Brasileira de Fruticultura, v.11, n.1, p.31-33, 1989.

MELO, A.S. de. Efeito de N, P e K sobre o desenvolvimento inicial e a nutrição foliar da aceroleira (Malpighia punicifolia L.). 1999. 81f. Dissertação (Mestrado) - Universidade Federal da Bahia, Cruz das Almas, 1999.

Ciência Rural, v.35, n.2, mar-abr, 2005. 
MOORBY, J.; BESFORD, R.T. Mineral nutrition and growth. In: GÖTTING, A.P.; HARVARD, M.H. Inorganic plant nutrition. Berlin : Springer-Verlag, 1983. V.15B, p.481-527.

PEIXOTO, J.R.; CARVALHO, M.L.M. Efeito da uréia, do sulfato de zinco e do ácido bórico na formação de mudas do maracujazeiro amarelo. Pesquisa Agropecuária Brasileira, v.31, n.5, p.325330,1996

PEREIRA, E.G. et al. Influência do nitrogênio mineral no crescimento e colonização micorrízica de mudas de árvores. Pesquisa Agropecuária Brasileira, v.31, n.9, p.53-662, 1996.

REVISTA PODER. Prontos para beber. Março, 2002. Disponível em $<\mathrm{http} / / \mathrm{www}$.poderonline.com.br $>$. On line. Acesso em: 25 de setembro, 2002

SALISBURY, F.B.; ROSS, C.W. Plant physiology. 4.ed. Belmont : Wadsworth, 1991. 682p. 